Provided for non-commercial research and education use. Not for reproduction, distribution or commercial use.

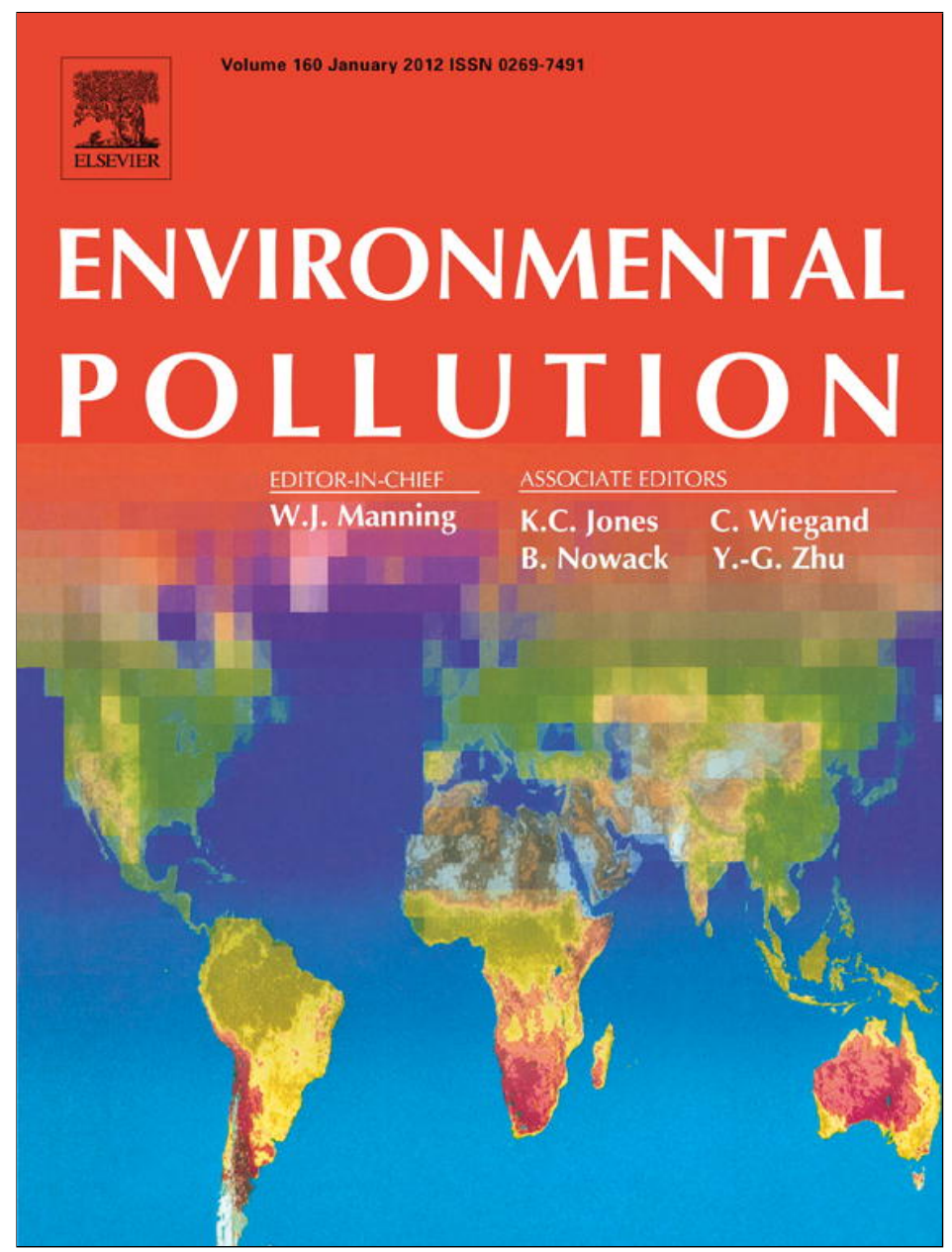

(This is a sample cover image for this issue. The actual cover is not yet available at this time.)

This article appeared in a journal published by Elsevier. The attached copy is furnished to the author for internal non-commercial research and education use, including for instruction at the authors institution and sharing with colleagues.

Other uses, including reproduction and distribution, or selling or licensing copies, or posting to personal, institutional or third party websites are prohibited.

In most cases authors are permitted to post their version of the article (e.g. in Word or Tex form) to their personal website or institutional repository. Authors requiring further information regarding Elsevier's archiving and manuscript policies are encouraged to visit:

http://www.elsevier.com/copyright 


\title{
Evaluation of the performance and limitations of empirical partition-relations and process based multisurface models to predict trace element solubility in soils
}

\author{
Jan E. Groenenberg ${ }^{\mathrm{a}, *}$, Joris J. Dijkstra ${ }^{\mathrm{b}}$, Luc T.C. Bonten ${ }^{\mathrm{a}}$, Wim de Vries ${ }^{\mathrm{a}, \mathrm{c}}$, Rob N.J. Comans ${ }^{\mathrm{b}, \mathrm{d}}$ \\ a Alterra, Wageningen UR, P.O. Box 47, 6700 AA Wageningen, The Netherlands \\ ${ }^{\mathrm{b}}$ Energy Research Centre of the Netherlands, P.O. Box 1, 1755 ZG Petten, The Netherlands \\ ${ }^{\mathrm{c}}$ Department of Environmental Systems Analysis, Wageningen University, Wageningen UR, P.O. Box 47, 6700 AA Wageningen, The Netherlands \\ ${ }^{\mathrm{d}}$ Department of Soil Quality, Wageningen University, Wageningen UR, P.O. Box 47, 6700 AA Wageningen, The Netherlands
}

\section{A R T I C L E I N F O}

\section{Article history:}

Received 24 October 2011

Received in revised form

26 February 2012

Accepted 6 March 2012

\section{Keywords:}

Trace element

Modeling

Solid solution partitioning

Chemical speciation

Soil

\begin{abstract}
A B S T R A C T
Here we evaluate the performance and limitations of two frequently used model-types to predict trace element solubility in soils: regression based "partition-relations" and thermodynamically based "multisurface models", for a large set of elements. For this purpose partition-relations were derived for As, Ba, Cd, $\mathrm{Co}, \mathrm{Cr}, \mathrm{Cu}, \mathrm{Mo}, \mathrm{Ni}, \mathrm{Pb}, \mathrm{Sb}, \mathrm{Se}, \mathrm{V}, \mathrm{Zn}$. The multi-surface model included aqueous speciation, mineral equilibria, sorption to organic matter, Fe/Al-(hydr)oxides and clay. Both approaches were evaluated by their application to independent data for a wide variety of conditions. We conclude that Freundlich-based partition-relations are robust predictors for most cations and can be used for independent soils, but within the environmental conditions of the data used for their derivation. The multisurface model is shown to be able to successfully predict solution concentrations over a wide range of conditions. Predicted trends for oxy-anions agree well for both approaches but with larger (random) deviations than for cations. (c) 2012 Elsevier Ltd. All rights reserved.
\end{abstract}

\section{Introduction}

Solid solution partitioning and solution speciation largely determine the availability of trace elements to biota and their mobility in soils. Models are frequently used tools to evaluate trace metal speciation in soils, for instance in relation with leaching and runoff (Tipping et al., 2006; Bonten et al., 2008b) and bioavailability (Thakali et al., 2006). Two distinct approaches are used to describe solid-solution partitioning in soils: (i) Empirical "partition-relations" relate the partitioning of elements to soil properties like $\mathrm{pH}$ and SOM. Model coefficients for such relations are generally derived from data of soil and corresponding solution extracts using (multiple) linear regression analysis (Sauvé et al., 2000); (ii) Process based "multisurface models" describe the various processes and interactions between the soil solution and reactive surfaces by combining separate models for ion-binding to the distinguished reactive surfaces (Bonten et al., 2008a). Intrinsic model parameters are derived from laboratory experiments on isolated or synthesized model systems (Dzombak and Morel, 1990; Milne et al., 2003). In the development of these two categories of models different

\footnotetext{
* Corresponding author.

E-mail addresses: bertjan.groenenberg@wur.nl (J.E. Groenenberg), jjdijkstra@ ecn.nl (J.J. Dijkstra), luc.bonten@wur.nl (L.T.C. Bonten), wim.devries@wur.nl (W. de Vries), comans@ecn.nl (R.N.J. Comans).
}

choices have been made that determine their performance and the width of their applicability.

\subsection{Empirical partition-relations}

Sorption data of trace elements to individual soils have been fitted successfully using Langmuir or Freundlich type models or a constant distribution coefficient $\left(K_{\mathrm{d}}\right)$ for a limited concentration range. Such empirical partition-relations lump sorption mechanisms including chemisorption, electrostatic sorption and surface precipitation to various reactive surfaces in soils including organic matter, clay and metal oxides. Adsorption constants may vary by orders of magnitude among soils and environmental conditions (Sauvé et al., 2000). To widen the applicability of partition-relations to various soils and environmental conditions, distribution coefficients $\left(K_{\mathrm{d}}\right.$-relation) (Janssen et al., 1997; Sauvé et al., 2000) have been related to soil properties. To account for non-linearity at larger concentration intervals, also Freundlich type partition-relations have been derived. Depending on the parameter for which the relation is optimized, these can be classified (Groenenberg et al., 2010b) as: (i) $\mathrm{C}-\mathrm{Q}$ relations directly relating solution concentrations (C) to solid phase concentrations $(\mathrm{Q})$ and soil properties (Sauvé et al., 2000) or vice versa (ii) Q-C relations (Elzinga et al., 1999) and (iii) $K_{\mathrm{f}}$-relations by relating the adsorption constant $K_{\mathrm{f}}$ to soil properties (Groenenberg et al., 2010b). Partition relations are 
available to predict either the total (Janssen et al., 1997; Sauvé et al., 2000) or the free metal ion concentration in solution (Sauvé et al., 1997a; Tipping et al., 2003; Groenenberg et al., 2010b). Methodological aspects are described in two recent publications (Degryse et al., 2009; Groenenberg et al., 2010b). The empirical approach is popular because of its simplicity, low data demand and short computing time, which makes these models easy to use in large scale (regional) applications (Bonten et al., 2008b; De Vries et al., 2008) and broadly accessible web-applications.

\subsection{Process based multisurface modeling}

Multisurface models combine thermodynamic models for inorganic speciation and mineral equilibria with separate models for ion binding to various reactive surfaces (also referred to as surface complexation). The explicit consideration of the underlying molecular processes distinguishes multisurface models from the partition relations in which all these processes are lumped into a single equation. The ion binding models are based on general thermodynamical principles. However, the complexity of ion binding to heterogeneous surfaces, especially organic matter, requires simplifications in order to obtain models that are feasible in practice (Van Riemsdijk et al., 2006). Model parameters are obtained by fitting the model to adsorption data for single reactive surfaces in well-defined experimental systems. Although by the nature of this parameterization these models may not be considered truly mechanistic, they distinguish explicitly between electrostatic and ion-specific binding and account for competition between ions. This makes these models independent of environmental conditions (e.g. pH, ionic strength) and suitable for predictions outside the range of conditions at which the parameters were fitted (Koopal et al., 2001). The intrinsic model parameters of the surface complexation models are usually derived for a large range of element concentrations and conditions (Dzombak and Morel, 1990; Milne et al., 2003). Within model applications to natural waters and soils (Benedetti et al., 1996; Lofts and Tipping, 1998; Weng et al., 2001; Tipping et al., 2003; Gustafsson, 2006; Almas et al., 2007; Bonten et al., 2008a; Butler et al., 2008; Dijkstra et al., 2009) a few models are notably frequently used. The NICA-Donnan model (Kinniburgh et al., 1999), WHAM-Model V/VI (Tipping, 1998) and related models (Gustafsson, 2001) are most often used to describe ion binding to organic matter. Ion binding to $\mathrm{Al} / \mathrm{Fe} / \mathrm{Mn}$-(hydr)oxides is frequently modeled using the generalized two layer model (GTLM) (Dzombak and Morel, 1990) developed for ion-binding to hydrous ferric oxide (HFO) and/or CD-MUSIC (Hiemstra and Van Riemsdijk, 1996) that was developed originally for ion-binding to crystalline ferric oxide. The availability of extended sets of generic model parameters for the NICADonnan model (Milne et al., 2003) and the GTLM model (Dzombak and Morel, 1990) has strongly facilitated their applicability. To date, multisurface models have been used primarily to aid our understanding of complex natural systems. However, their generic basis makes them also suitable for generic risk assessments, e.g., as demonstrated for the derivation of limits for contaminant emission from construction materials to protect soil and groundwater (Verschoor et al., 2008).

\subsection{Generic model application and aim of the study}

In this study we compare the performance of both types of models independently in view of their application in science, risk assessment and legislation. Although fitting of models may give better results for individual cases from which the fitted parameters are derived, it also leads to conditionality. Here we have explicitly selected generic models because we aim for a generic applicability. When applying partition models, attention should be paid to conditionality resulting from: (i) the choice of parameters incorporated in the model, which may vary from one parameter, e.g. pH (Sauvé et al., 2000), or few parameters e.g. pH, SOM (Sauvé et al., 2000; Groenenberg et al., 2010b) to multiple parameters (Janssen et al., 1997; Elzinga et al., 1999); (ii) the soil types included in the derivation set, ranging from a specific group of, e.g. organic, soils (Tipping et al., 2003) to a large variety of soil types (Groenenberg et al., 2010b); (iii) the simplicity of the model which lumps several processes, e.g. by using only a single coefficient for the $\mathrm{pH}$ dependence of ion-binding to both organic matter and oxides, hydrolysis and the pH-dependent concentration of important competing cations such as Al, Fe and Ca, and (iv) the optimization method of the model, which allows either the prediction of solution concentrations $(\mathrm{C}-\mathrm{Q})$, solid phase concentrations $(\mathrm{Q}-\mathrm{C})$ or sorption constant $\left(K_{\mathrm{d}} / K_{\mathrm{f}}\right)$ (Groenenberg et al., 2010b). Multisurface models are hypothesized to be less conditional and give better predictions for a wider range of conditions. In these models, conditionality may arise from specific choices in model setup and parameterization, e.g. the selection of reactive surfaces, and appropriate mineral equilibria that control the element solubility at high concentrations (Bonten et al., 2008a).

It is not yet clear to which extent the conditional character of partition-relations permits their use to predict trace element solubility in particularly the following situations: (1) for soils that are not part of the dataset that was used for their derivation; (2) for conditions/soil properties outside the domain of the derivation set; and (3) at changing environmental conditions (e.g. $\mathrm{pH}$ ) for individual soils. In the context of their generic application, the aim of this study is to independently evaluate both approaches for a large range of elements, including metal cations and oxy-anions, with regard to their accuracy to predict solution concentrations, and to identify the ranges of conditions for which they can be applied. Previous studies were either limited to the evaluation of multisurface models (Lofts and Tipping, 1998; Weng et al., 2001; Gustafsson and Van Schaik, 2003; Schröder et al., 2005; Bonten et al., 2008a; Dijkstra et al., 2009) or partition-relations (Janssen et al., 1997; Sauvé et al., 2000; Tipping et al., 2003) separately. Moreover, these studies have only evaluated the performance of partition relations to fit the data from which they were derived. We found only one study, limited to a single soil type, in which both approaches were evaluated to predict the concentrations of four metals $(\mathrm{Cd}, \mathrm{Cu}, \mathrm{Pb}, \mathrm{Zn})$ on independent data (Vijver et al., 2008). Here we present newly-derived partitionrelations for a large number of elements, i.e. $\mathrm{As}, \mathrm{Ba}, \mathrm{Cd}, \mathrm{Co}, \mathrm{Cr}, \mathrm{Cu}, \mathrm{Mo}$, $\mathrm{Ni}, \mathrm{Pb}, \mathrm{Sb}, \mathrm{Se}, \mathrm{V}$ and $\mathrm{Zn}$, and results of both their performance, and that of a multisurface model, on independent data for a large range of element concentrations, soils and environmental (yet limited to moderately oxidized) conditions.

\section{Materials and methods \\ 2.1. Derivation of partition-relations}

We derived Freundlich-type partition-relations, specifically $\mathrm{C}-\mathrm{Q}$ relations as being the most representative presently used (Sauvé et al., 2000; Tipping et al., 2003; Vijver et al., 2008; Groenenberg et al., 2010b; Rodrigues et al., 2010). Furthermore these relations have been shown to be the best predictor for solution concentrations (Sauvé et al., 2000; Groenenberg et al., 2010b) because their parameters are optimized to minimize the error in the predicted solution concentration. We used an extended set of potential model coefficients (Eq. (1)) and a dataset with a large variety in soil types, soil properties, element concentrations and environmental conditions for the derivation of the partition-relations, to minimize the conditionality with respect to points (i, ii) listed in the introduction:

$\log C=\alpha_{0}+\alpha_{1} \cdot \log Q+\alpha_{2} \cdot \log \mathrm{SOM}+\alpha_{3} \cdot \log$ clay $+\alpha_{4} \cdot \log \mathrm{AlFe}_{\mathrm{ox}}+\alpha_{5} \cdot \log \mathrm{DOC}+\alpha_{6} \cdot \mathrm{pH}$

With $C$ =element concentration in solution $\left(\mathrm{mol} \mathrm{L}^{-1}\right), Q=$ (reactive) element content, extracted with $0.43 \mathrm{M} \mathrm{HNO}_{3}\left(\mathrm{~mol}_{\mathrm{kg}}{ }^{-1}\right), \mathrm{SOM}=$ soil organic matter content $(\%), \mathrm{DOC}=$ dissolved organic carbon $\left(\mathrm{mg} \mathrm{L}^{-1}\right)$, clay = clay content $(\%)$, and $\mathrm{AlFe}_{\mathrm{ox}}$ the sum of oxalate extractable $\mathrm{Al}$ and $\mathrm{Fe}\left(\mathrm{mmol} \mathrm{kg}^{-1}\right)$. The coefficients of Eq. (1) were derived by multiple regression (Genstat Release 12.1) using dataset NL only 
(Groenenberg et al., 2010b). Soil characteristics are listed in Table 1; correlations between the parameters are listed in Table S-2 of the supporting information. All possible combinations of parameters in Eq. (1) were evaluated by stepwise regression but only those parameters were chosen which added to the explained variance $\left(R_{\mathrm{adj}}^{2}\right)$ and were significant at the 0.005 probability level. Dataset NL includes reactive element contents, soil properties, analyses of various solution extracts (Table S-1 supporting information) for $\mathrm{Cd}, \mathrm{Cu}, \mathrm{Ni}, \mathrm{Pb}$ and $\mathrm{Zn}$ (118 soils, 403 solution extracts) and $\mathrm{As}, \mathrm{Ba}, \mathrm{Co}, \mathrm{Cr}$, Mo, Sb, Se, V (70 soils, $700.01 \mathrm{M} \mathrm{CaCl}_{2}$-extracts,).

\subsection{Multisurface model}

The multisurface model setup was adopted from Dijkstra et al. (2009). The model includes the NICA-Donnan model (Kinniburgh et al., 1999) for ion binding to SOM and dissolved organic matter (DOM), the generalized two layer model (GTLM) (Dzombak and Morel, 1990) for ion binding to Fe /Al(hydr)oxides and a Donnan model for binding to clay. Model inputs include (1) "reactive" contents, extracted with $0.43 \mathrm{M} \mathrm{HNO}_{3}$, of the considered elements including sulfur, which in the form of sulfate competes for binding with oxy-anions, (2) measured $\mathrm{pH}$ and total dissolved concentrations of major cations and anions including $\mathrm{PO}_{4}^{3-}, \mathrm{CO}_{3}^{2-}$ and $\mathrm{H}_{3} \mathrm{SiO}_{4}^{-}$, to account for competition effects, (3) concentrations of the different reactive surfaces (see supporting information), and (4) generic model parameters for the NICADonnan (Milne et al., 2003) and GTLM (Dzombak and Morel, 1990) models with some parameters for additional elements from Dijkstra et al. (2009). The redox status of the soil (pe) was set according to $\mathrm{pH}+\mathrm{pe}=11$ which is a representative value for aerobic soils (Baas Becking et al., 1960).

\subsection{Model evaluation}

We evaluated the performance of both the partition relations and the multisurface model on independent data from three data sets (NB, PRT and pH-stat, Table 1), without any parameter fitting prior to their application. The performance was evaluated quantitatively on the basis of the Root Mean Square Error (RMSE) and Mean Error (ME) of the log transformed predicted solution concentrations. Because dataset NL was used to derive the partition relations, it was excluded from the quantitative evaluation of model performance. Measurements and predicted concentrations of dataset NL are, however, included in the graphs for visual comparison. The datasets include "reactive" element contents extracted with $0.43 \mathrm{M}$ $\mathrm{HNO}_{3}$ (Gooddy et al., 1995; Tipping et al., 2003; Dijkstra et al., 2009; Groenenberg et al., 2010b; Rodrigues et al., 2010), contents of reactive soil constituents and corresponding solution data. A detailed description is given in the original publications and the supporting information. A subset was used of dataset PRT (Rodrigues et al., 2010), containing various contaminated soils from Portugal, using only the filtered $0.01 \mathrm{M} \mathrm{CaCl}_{2}$-extracts. Dataset NB contains soil data obtained from a wastewater infiltration field (Koopmans and Groenenberg, 2011); the solution was obtained both by centrifugation and extraction with $0.002 \mathrm{M} \mathrm{CaCl}_{2}$. Dataset $\mathrm{pH}$-stat contains solution data obtained from $\mathrm{pH}$-static experiments ( $\mathrm{pH} \mathrm{2-12)}$ previously used to evaluate the multisurface model (Dijkstra et al., 2009). This dataset was used to explicitly test the models on their ability to predict the $\mathrm{pH}$ dependent solubility of individual soil samples.

\section{Results and discussion}

\subsection{Partition-relations}

Together with the study by Rodrigues et al. (2010) this is the first study with partition-relations for such a large set of elements. The optimized coefficients for the partition-relations are summarized in Table 2, including the explained variance $\left(R_{\mathrm{adj}}^{2}\right)$ and the Root Mean Square Error (RMSE) of the fit to the solution concentrations. Using the stepwise regression method, we found 3-5 significant

Table 1

Overview of soil datasets.

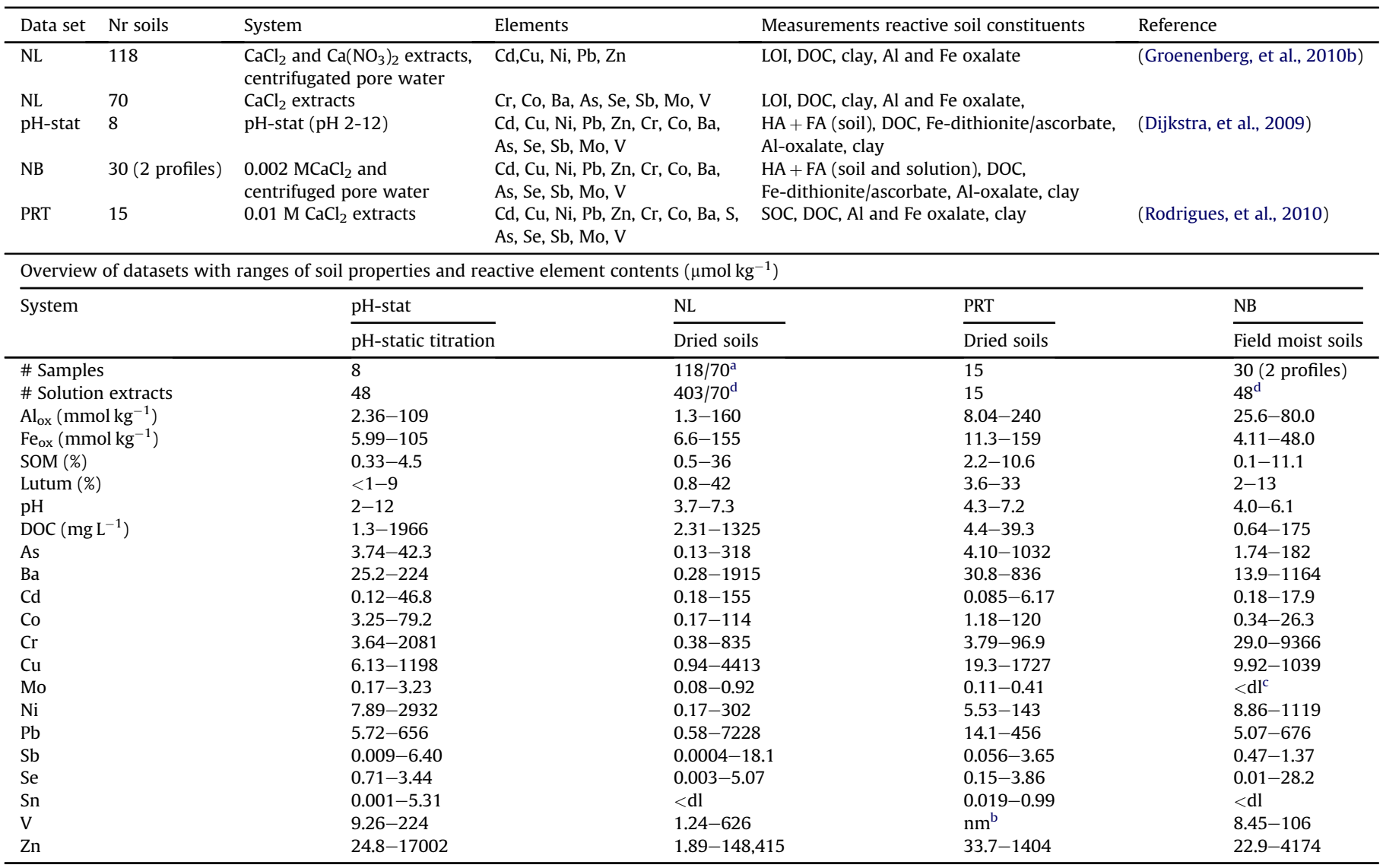

a 118 soils $\mathrm{Cd}, \mathrm{Cu}, \mathrm{Ni}, \mathrm{Pb}$ and $\mathrm{Zn} ; 70$ soils with all elements.

b $\mathrm{nm}=$ not measured

c $<$ Detection limit.

d There are also data based on pore water obtained by centrifugation of field moist soils for a subset of 49 soils in dataset NL and 12 samples in dataset NB. 
Table 2

Coefficients partition relations (Eq. 1)

\begin{tabular}{|c|c|c|c|c|c|c|c|c|c|}
\hline & $\alpha_{0}$ & $\begin{array}{l}\alpha_{1} \\
(\mathrm{Q})\end{array}$ & $\begin{array}{l}\alpha_{2} \\
\text { (SOM) }\end{array}$ & $\begin{array}{l}\alpha_{3} \\
\text { (Clay) }\end{array}$ & $\begin{array}{l}\alpha_{4} \\
\text { (AlFe) }\end{array}$ & $\begin{array}{l}\alpha_{5} \\
\text { (DOC) }\end{array}$ & $\begin{array}{l}\alpha_{6} \\
(\mathrm{pH})\end{array}$ & $\mathrm{R}^{2}$ adj & RMSE \\
\hline As & -4.64 & 0.59 & - & - & -0.72 & 0.91 & - & 0.72 & 0.35 \\
\hline $\mathrm{Ba}$ & -2.16 & 0.71 & - & -0.30 & - & - & -0.15 & 0.67 & 0.35 \\
\hline $\mathrm{Cd}$ & 1.60 & 1.11 & -0.62 & - & -0.39 & 0.29 & -0.41 & 0.82 & 0.34 \\
\hline Co & 1.49 & 0.93 & -0.20 & - & - & - & -0.79 & 0.90 & 0.25 \\
\hline $\mathrm{Cr}$ & -5.64 & 0.32 & - & - & -0.24 & 0.49 & -0.15 & 0.76 & 0.18 \\
\hline $\mathrm{Cu}$ & -3.74 & 0.60 & -0.28 & - & -0.79 & 0.79 & - & 0.56 & 0.42 \\
\hline Mo & -8.78 & 0.36 & 1.54 & -0.52 & -0.98 & - & 0.64 & 0.63 & 0.38 \\
\hline $\mathrm{Ni}$ & -1.95 & 0.80 & -0.77 & -0.17 & - & 0.63 & -0.25 & 0.62 & 0.40 \\
\hline $\mathrm{Pb}$ & -2.08 & 0.79 & -0.40 & - & -0.83 & 0.88 & -0.29 & 0.63 & 0.67 \\
\hline $\mathrm{Sb}$ & -6.43 & 0.20 & - & - & -0.29 & 0.33 & - & 0.62 & 0.18 \\
\hline Se & -8.56 & 0.11 & - & - & - & 0.57 & 0.07 & 0.69 & 0.20 \\
\hline V & -2.67 & 0.98 & - & -0.64 & -1.06 & 1.24 & - & 0.71 & 0.43 \\
\hline $\mathrm{Zn}$ & 0.93 & 0.99 & -0.43 & -0.22 & -0.14 & 0.12 & -0.46 & 0.83 & 0.39 \\
\hline
\end{tabular}

parameters for most elements. Other studies have generally reported regression relations with fewer parameters, either because the available datasets included less parameters (e.g. Sauvé et al., 1997b, 2000; Tipping et al., 2003) or less soil samples (e.g. Janssen et al., 1997). In a study with a similar set of parameters, Anderson and Christensen (1988) derived $K_{\mathrm{d}}$-relations with four significant $(p<0.001)$ parameters. Results of the stepwise regression method (Table S-3 supporting information) indicate that the most important parameters for the metal cations $\mathrm{Ba}, \mathrm{Cd}, \mathrm{Co}, \mathrm{Ni}, \mathrm{Pb}$ and $\mathrm{Zn}$ are the reactive metal content $(\mathrm{Q})$ and $\mathrm{pH}$, whereas for $\mathrm{Cu}$ and $\mathrm{Cr}$, DOC was the most important parameter. For the oxy-anions and $\mathrm{V}$, the reactive metal content $(\mathrm{Q})$ and DOC were the most important parameters. The explained variance and RMSE are generally good $\left(R_{\mathrm{adj}}^{2}>0.62\right.$, RMSE $<0.41$ ), except for $\mathrm{Cu}$, Mo (low $R_{\mathrm{adj}}^{2}$ ) and $\mathrm{Pb}$ (high RMSE $\left.=0.67\right)$ and similar to previous studies for $\mathrm{Cd}, \mathrm{Cu}, \mathrm{Ni}, \mathrm{Pb}$ and $\mathrm{Zn}$ (Elzinga et al., 1999; Sauvé et al., 2000). Coefficients for solid phase concentrations are always positive but low for $\mathrm{Cr}$, Mo, Sb and Se, indicating only a small influence of the solid phase concentration on solution concentrations. The sign of the regression coefficients is consistent with the known soil chemistry of the different elements. For the cationic metals, coefficients for $\mathrm{pH}$ are always negative, reflecting an increasing metal binding with $\mathrm{pH}$ resulting from a decreasing competition of protons for binding to SOM and $\mathrm{Al} / \mathrm{Fe}$-(hydr)oxides. Remarkably, $\mathrm{pH}$ is not a significant parameter for the $\mathrm{Cu}$ concentration, which was observed also by Sauvé et al. (1997b). This is possibly due to its particularly high affinity for organic matter and the very similar influence of $\mathrm{pH}$ on $\mathrm{Cu}$ binding to both SOM and DOM. Conversely, $\mathrm{pH}$-coefficients for oxy-anions, when significant, are always positive, reflecting a decreasing sorption due to a decrease of positive surface charge of $\mathrm{Al} / \mathrm{Fe}$-(hydr)oxides with increasing $\mathrm{pH}$. Despite the fact that SOM and DOM were strongly correlated (Table S-2 supporting information) we always found significant and plausible coefficients for both SOM and DOM for metal cations and only significant coefficients for DOC for oxy-anions (i.e., not for SOM). Coefficients for SOM were always negative for cationic species, consistent with their binding to organic matter. Coefficients for DOC were positive for both cations and oxy-anions. For cationic metals, this relationship is consistent with their binding affinity for DOC, with high coefficients for $\mathrm{Cu}, \mathrm{Pb}$ and $\mathrm{V}$ which have a particularly high affinity to bind to organic matter. The positive relation of oxy-anion concentrations with DOC is probably due to the very similar binding of the oxy-anions and (anionic) DOC to oxide surfaces and their mutual competition in that process (Gustafsson, 2006; Van Riemsdijk et al., 2006; Weng et al., 2009). The small values of the regression-coefficients for the reactive solid phase concentrations of $\mathrm{Cr}$, Mo, Sb and Se could reflect either depletion of these elements in the solid phase, as a result of the high liquid to solution ratio (LS10), or solubility control by a mineral phase. However, depletion is more likely for $\mathrm{Sb}$, of which on average $45 \%$ of reactive metal was dissolved, than for $\mathrm{Cr}$ and Se for which dissolution was $10 \%$ or less. Further, concentrations of Sb and Se are most likely regulated by sorption reactions (McBride, 1994) and not by mineral equilibria. Although $\mathrm{Cr}$ has been reported to be controlled by the solubility of $\mathrm{Cr}$-containing oxides (McBride, 1994), the used multisurface model resulted in adequate predictions of $\mathrm{Cr}$ concentrations by sorption to organic matter (Dijkstra et al., 2009). Altogether this means that we have no plausible explanation yet for the very small values of the regression-coefficients for the solid phase concentrations of $\mathrm{Cr}$, Mo, Sb and Se.

\subsection{Evaluation partition-relations}

Fig. 1 shows predictions of the partition-relations as a function of $\mathrm{pH}$ for the pH-stat data and shows predicted vs. measured concentrations for both the partition-relations and multisurface model for all data sets. Model performance is quantified using the RMSE and ME of the predictions (Fig. 2). The partition-relations predict the concentration level of the metal cations $\mathrm{Cd}, \mathrm{Cu}, \mathrm{Ni}$, and $\mathrm{Zn}$ well (RMSE $\leq 0.45$ ). Predicted concentrations of the oxy-anions As, Mo, Sb and Se showed somewhat higher deviation from the measured values $(0.55 \leq \mathrm{RMSE} \leq 0.69)$ in the most relevant $\mathrm{pH}$ range $3-8$, without any trend in the errors with $\mathrm{pH}$ (Fig. S-1 supporting information). This performance is also reflected by the remarkably well predicted $\mathrm{pH}$ dependence for individual soils (Fig. 1), which allows the use of partition-relations in predictive simulations under changing $\mathrm{pH}$. The latter was not a priori expected, because the pH-coefficient is optimized by comparing different samples at their natural $\mathrm{pH}$, rather than by optimizing the solution concentration for individual soils over a range of $\mathrm{pH}$ (Tipping et al., 2003; Groenenberg et al., 2010b). Predictions for the other cations $\mathrm{Ba}, \mathrm{Co}, \mathrm{Cr}, \mathrm{Pb}, \mathrm{V}$ (predominantly present as $\mathrm{VO}^{2+}$ under acidic conditions according to speciation calculations (Dijkstra et al., 2009)), have a larger RMSE (Fig. 2). The partition-relation fails for $\mathrm{Ba}$, likely because of the different mechanisms which control its solubility at different $\mathrm{pH}$ : according to the multisurface model calculations, Ba solubility is controlled by barite and sorption to clay under acidic conditions and sorption to SOM under neutral and alkaline conditions (Dijkstra et al., 2009). Predicted concentrations of $\mathrm{Co}$ are generally good below $\mathrm{pH} 6$ but too low at higher $\mathrm{pH}$ : according to the multisurface model calculations, Co solubility is controlled by sorption to organic matter under acidic conditions and sorption to $\mathrm{Al} / \mathrm{Fe}$-(hydr)oxides under neutral and alkaline conditions (Dijkstra et al., 2009). The partition model overestimates $\mathrm{Cr}$ and $\mathrm{Pb}$ concentrations in the low concentration range whereas it underestimates concentrations in the higher concentration range. This effect is most pronounced for $\mathrm{Cr}$. The high RMSE for $\mathrm{V}$ is particularly due to the large deviations for dataset NB for which we do not have an explanation.

Outside the $\mathrm{pH}$ range $3-8$, i.e. outside the range of the data from which the partition relations were derived, the partition-relations show a clearly lower performance especially in the high $\mathrm{pH}$ range. At high $\mathrm{pH}$ the partition-relations underestimate cation concentrations which increase due to hydrolysis reactions and stronger binding to DOM. Cu concentrations were, however, remarkably well predicted because of their strong correlation with (measured) DOC. At very low $\mathrm{pH}$ the model underestimates concentrations of $\mathrm{Cu}, \mathrm{Pb}$ and V, i.e. the cations which bind very strongly to SOM. Predicted concentrations of weakly binding cations such as $\mathrm{Cd}$, Co and $\mathrm{Zn}$ now sometimes exceed the total amount present because the partition relations do not account for the mass balance. Remarkably, the partition relations adequately predict $\mathrm{pH}$-dependent solubility of Se 

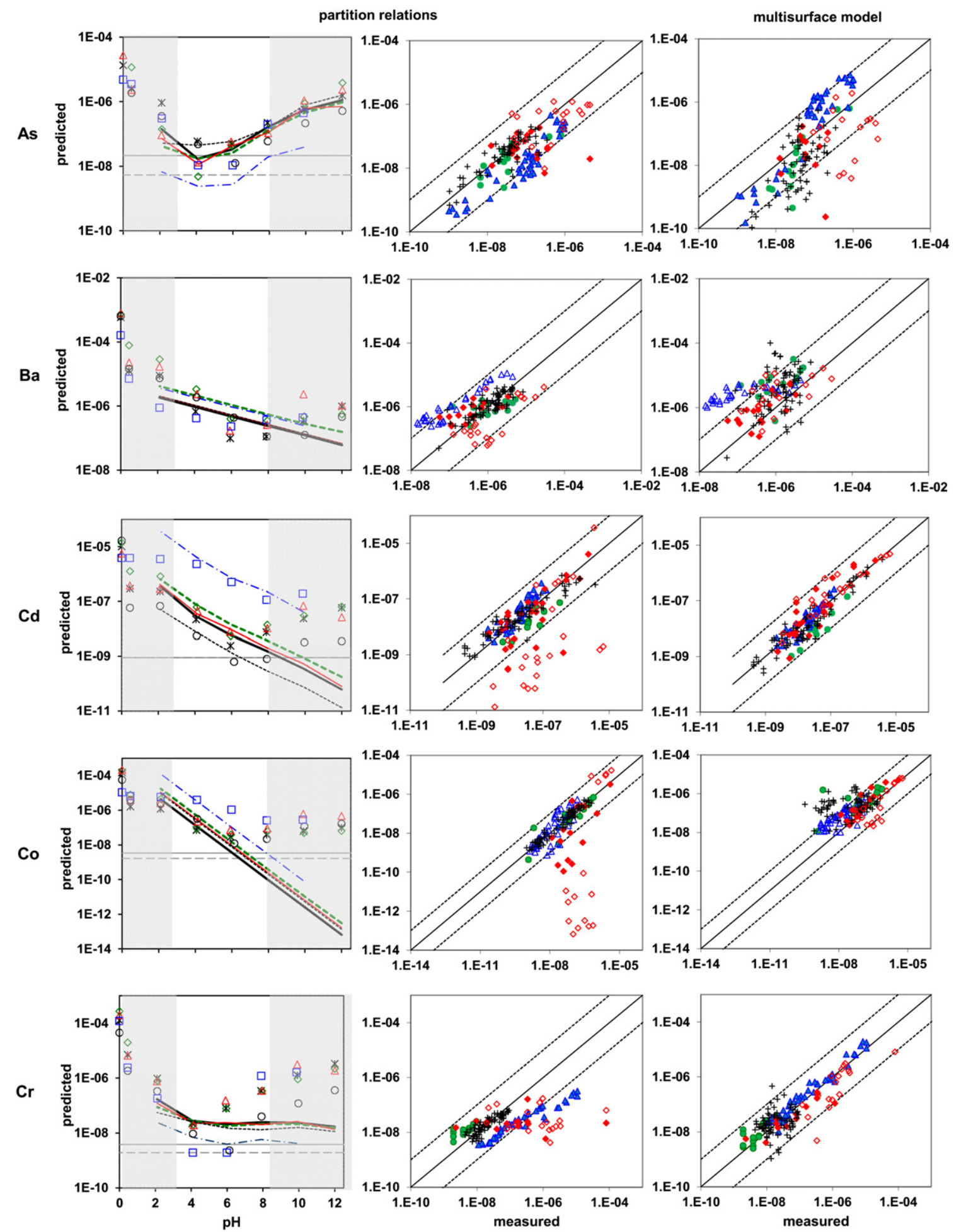

Fig. 1. Left panels: predictions partition relations of the $\mathrm{pH}$-stat data as function of $\mathrm{pH}$ (symbols represent measurements, lines represent model predictions), total reactive concentrations, recalculated to $\mathrm{mol} / \mathrm{L}$, are shown at $\mathrm{pH} 0.5$; Middle and right panels comparison of predictions for all datasets by the partition-model (middle panels) and multisurface model (right panels). Open symbols represent measurements outside pH range 3-8.

and As also at low and high $\mathrm{pH}$. This is especially clear from the $\mathrm{pH}-$ stat data (Fig. 1). Given that the pH-coefficient of these elements was either insignificant or very small, the high value for the DOC coefficient supports our previously stated hypothesis that this performance results from the similar, and therefore strongly correlated, $\mathrm{pH}$ dependence of DOC and oxy-anion binding to oxide-surfaces.
For Mo and $\mathrm{Sb}$ a somewhat different relation was found, including a positive $\mathrm{pH}$-coefficient. However, their concentrations are increasingly underestimated with decreasing $\mathrm{pH}$.

We evaluated a possible improved performance of the partition relations over a wider $\mathrm{pH}$ range by inclusion of the $\mathrm{pH}$-stat data in the derivation set. The coefficients of the derived relations 

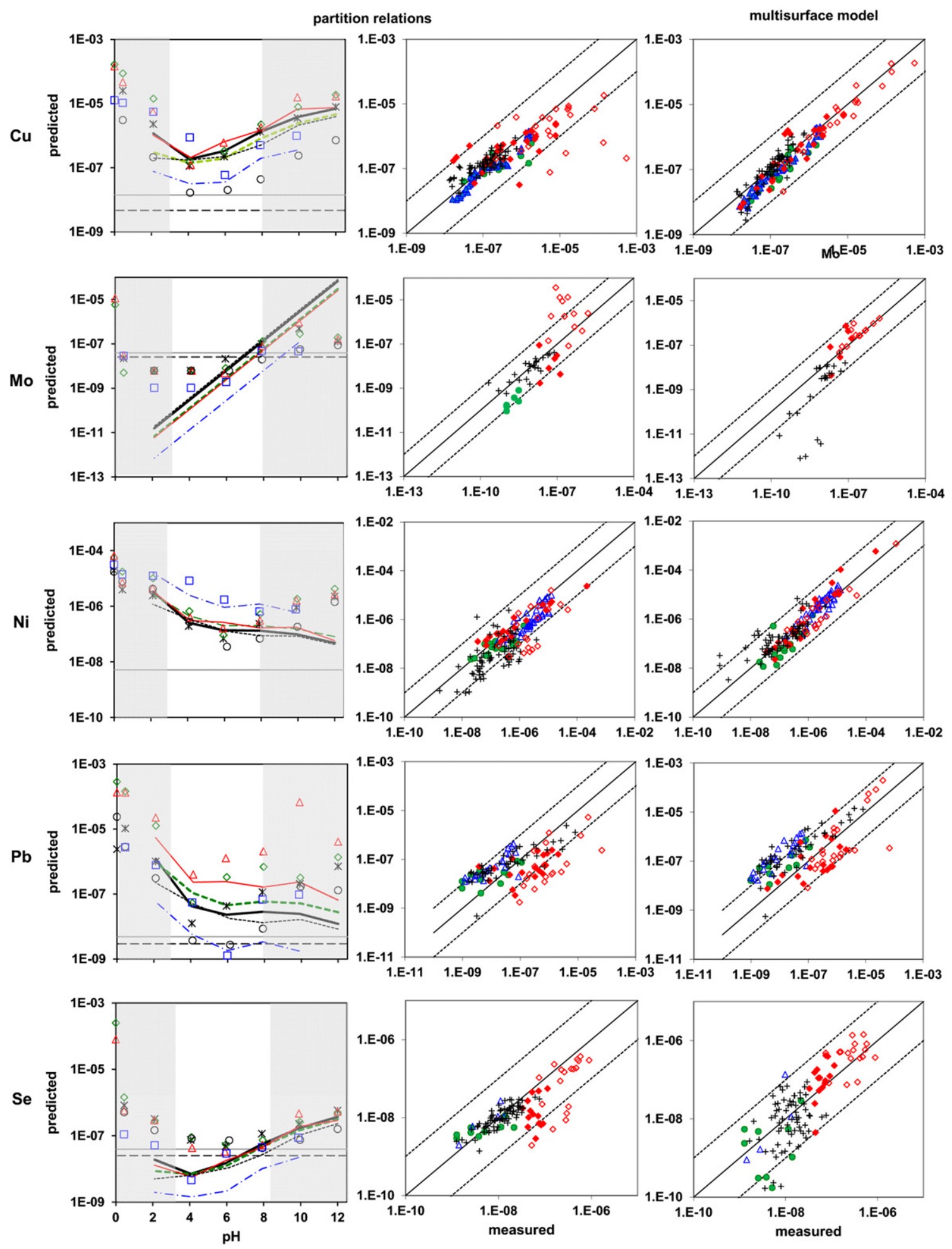

Fig. 1. (continued)

(Table S-4, supporting information) show an increasing importance of DOC together with a decreasing importance of the coefficient for $\mathrm{pH}$. Similar to our previous observation for the oxyanions, the $\mathrm{pH}$ dependence of the solubility for both metal cations and oxy-anions is now largely accounted for by the coefficient for DOC which shows a similar $\mathrm{pH}$-dependence. Remarkable is the decreasing importance of the coefficients for AlFeox, together with an increasing importance of clay and SOM, both for the metal cations and oxy-anions, which cannot be explained mechanistically. Inclusion of the $\mathrm{pH}$-stat data in the derivation set improves the model performance for all elements in the $\mathrm{pH}$ range 2-12 (Fig. S-2 in the supporting information) in terms of the RMSE (Fig. 2). Inclusion of the $\mathrm{pH}$-stat data improved predictions also in the $\mathrm{pH}$ range $3-8$ for those cations which form strong complexes 

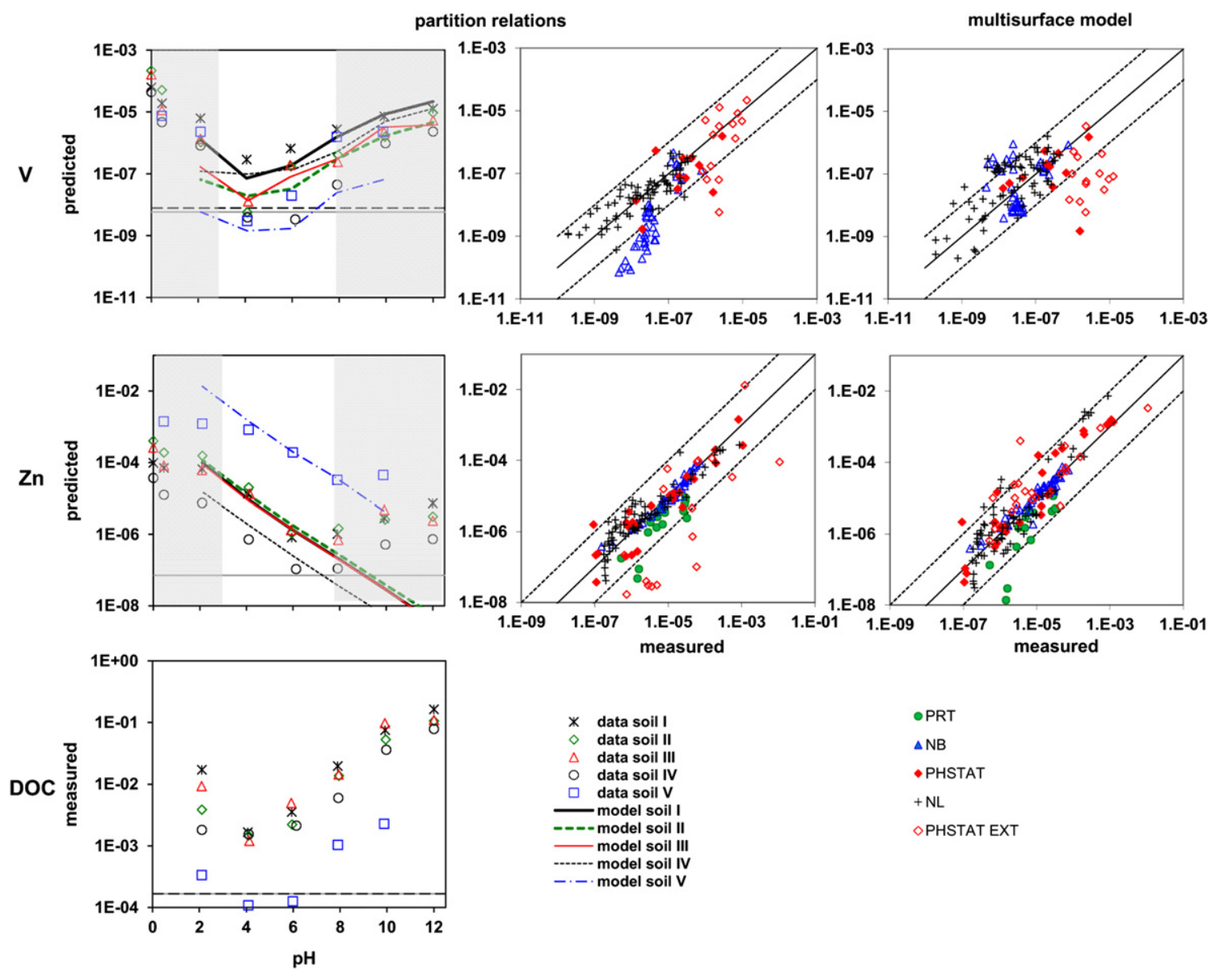

Fig. 1. (continued).

with DOC, i.e. $\mathrm{Cu}$ and $\mathrm{Cr}$, and for most of the oxy-anions: As, Se and Mo. For cations which solubility depends on $\mathrm{pH}$ rather than on DOC concentration ( $\mathrm{Cd}, \mathrm{Ni}$ and $\mathrm{Zn}$ ), the model performance, however, decreases between $\mathrm{pH} 3-8$, but remains still acceptable. For those elements for which the predictions were rather poor i.e. $\mathrm{Co}, \mathrm{Pb}$ and $\mathrm{Sb}$, model performance remains about the same in the pH range 3-8.

\subsection{Evaluation multisurface model}

Fig. 1 compares model predictions with measurements for all data sets. Model performance in terms of RMSE is presented in Fig. 2. The model predicts concentrations well over the entire pH-range (2-12) for most divalent cations, i.e. $\mathrm{Cd}, \mathrm{Cu}, \mathrm{Ni}$ and $\mathrm{Zn}$. For other cations, results are generally poorer. For $\mathrm{Pb}$, predicted concentrations are generally too high in the $\mathrm{pH}$ range $2-5$ where the multisurface model predicts $\mathrm{Pb}$ to bind predominantly to SOM. Conversely, concentrations are underestimated above $\mathrm{pH} 6$ where $\mathrm{Pb}$ is predicted to bind predominantly to $\mathrm{Al} / \mathrm{Fe}$-(hydr)oxides. Concentrations of $\mathrm{Ba}$ are predicted well in case the multisurface model predicts equilibrium with barite but $\mathrm{Ba}$ is over-predicted when the solubility is predicted to be controlled by sorption to SOM. Binding of Ba to OM is thus likely stronger than the current NICA-Donnan parameters predict. For Co both sorption to SOM (the dominant process at low $\mathrm{pH}$ ) and sorption to $\mathrm{HFO}$ (the dominant process at high $\mathrm{pH}$ ) are likely underestimated.
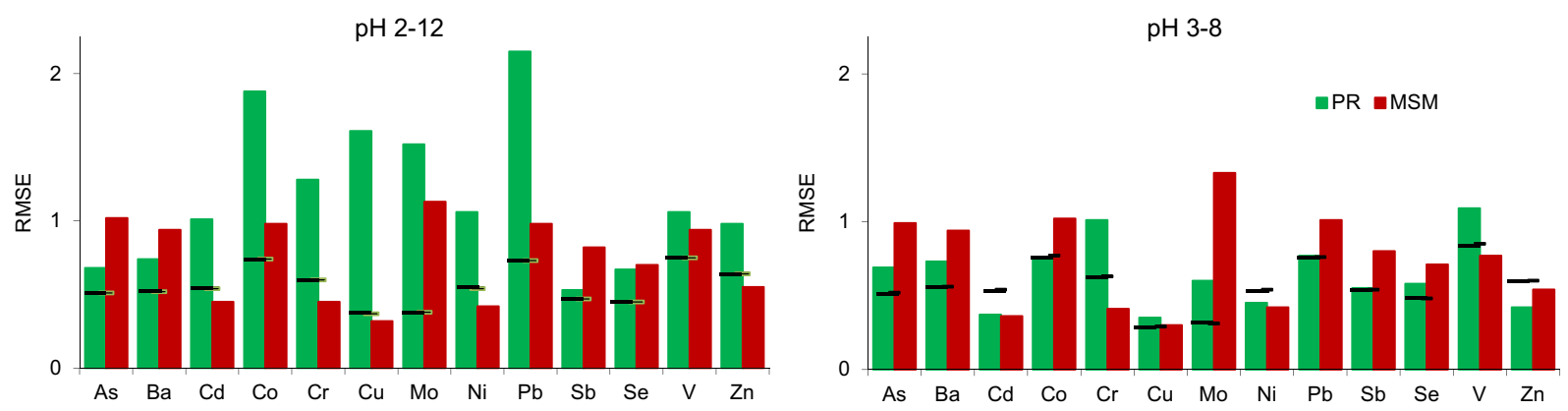

Fig. 2. Root Mean Square Error (RMSE) for the predictions of solute concentrations of the independent datasets for the partition relations (PR), multisurface model (MS) and partition relations derived from the extended dataset including the pH-stat data (lines) for the pH range 3-8 (left) and 2-12 (right). 
Despite the fact that the binding-constants for $\mathrm{Cr}$ are uncertain, given their origin in linear free energy relations (LFER) (Milne et al., 2003) the model gives very good predictions for the total solution concentration. We observed that these predictions were rather insensitive to the exact value of the binding constants. Varying the $\mathrm{Cr}$-HA binding-constants in the NICA-Donnan model by a factor 100 around their nominal value leads to a change of only $-9 \%$ and $+2 \%$ in the total solution concentrations. For elements with such high affinity, the model predicts almost complete binding to organic matter and the solution concentration is therefore largely determined by the ratio of DOM and SOM. Khai et al. (2008), however, found large deviations between modeled and measured total $\mathrm{Cr}$ concentrations using the NICA-Donnan model. Different from our approach in which both SOM and DOM were modeled as HA, they modeled SOM as HA and DOM as a mixture with equal amounts of HA and FA. The large deviations in their predictions are possibly due to the difference between the highly uncertain model parameters for HA and FA estimated by Milne et al. (2003) using LFER. The uncertainty in NICA-Donnan parameters, also resulted in large deviations between predicted and measured free $\mathrm{Cr}^{3+}$-ion concentrations in soil solution (Koopmans and Groenenberg, 2011).

Predictions for the oxy-anions As, Mo, Sb and Se reflect the trend of the solubility well but with a relatively large deviation (RMSE 0.7-1) compared to the cations. The (competitive) influence of DOM on oxy-anion binding (Gustafsson, 2006; Weng et al., 2009), which is not included in the model, may be a confounding factor. No specific relations were found between the error in the prediction and $\mathrm{pH}$, except for As that is underestimated at high $\mathrm{pH}$. Concentrations for $\mathrm{Sb}$ were systematically overestimated.

\subsection{Comparison between partition-relations and the multisurface model and implications for their use in risk assessment}

Within the relevant $\mathrm{pH}$ range for most soils, i.e. $\mathrm{pH} 3-8$, partition-relations and the multisurface model showed equal performance for metal cations according to the similar RMSE's of their predictions (Fig. 2). Partition-relations derived for the $\mathrm{pH}$ range 3-8 are less useful under extreme conditions (i.e. outside the range from which they were derived) such as at very low $\mathrm{pH}$, e.g. after oxidation of sulfidic sediments, and under alkaline conditions, e.g. calcareous soils and soils in contact with cementitious construction materials or after cement-stabilization. In such cases the multisurface model provides better predictions. Partition-relations are, however, shown to be robust predictors for concentrations of most of the evaluated divalent cations $(\mathrm{Cd}, \mathrm{Cu}$, $\mathrm{Ni}, \mathrm{Pb}$ and $\mathrm{Zn}$ ) for a large variety of soils and conditions, e.g. with liquid to solid ratios varying between 0.2 and 10 . The derived coefficients of the relations comply with our mechanistic picture of the controlling processes as described above. Furthermore, partition-relations are able to describe the $\mathrm{pH}$-dependence of divalent cation concentrations adequately within $\mathrm{pH}$ 3-8. Considering these $\mathrm{pH}$ boundaries, this performance legitimates the use of such relations in large scale applications of risk assessment models for these elements.

Predictions for oxy-anions seem to be somewhat less successful both by the partition-relations and the multisurface model, with larger deviations (Fig. 2), although the concentration trends are predicted well (Fig. 1). Predictions of the partition-relation for these elements are sensitive to the concentration of DOC that is input to the model, but this dependency does not necessarily have a mechanistic basis. In this respect, the multisurface model is mechanistically more transparent than the partition-relations.

For the elements which are already predicted well, i.e. the metal cations $\mathrm{Cd}, \mathrm{Cu}, \mathrm{Ni}, \mathrm{Pb}$ and $\mathrm{Zn}$, no large improvements can be expected with extension of datasets for derivation of $C-Q$ relations because the dataset used in this study already covers a large range of element concentrations and soil properties. This is also reflected by the similar good model performance for the independent datasets and the derivation set. Partition relations of the elements for which the predictions are relatively poor and for which the concentration ranges are relatively small, as for the oxy-anions and $\mathrm{Cr}$, can possibly be improved by extension of the datasets. For these elements model performance for the independent data-sets was systematically lower than that for the derivation set. It was expected that the simplicity of the present partition-relations puts some general constraints on their potential improvement. Although the dominant solubility controlling mechanisms vary with $\mathrm{pH}$, extension of the derivation set with data in the range $\mathrm{pH} 2-12$ leads to a substantial improvement of the fit to the data in this range, indicating a potential for improvement of these relations for predictions over a wider $\mathrm{pH}-$ range. Despite the fact that the various solubility controlling mechanisms are modeled explicitly in the multisurface approach, partition relations calibrated for the extended $\mathrm{pH}$ range generally show smaller RMSE's for most elements, except $\mathrm{Cd}, \mathrm{Cr}, \mathrm{Cu}, \mathrm{Ni}$ and $\mathrm{Zn}$, in the $\mathrm{pH}$ range 2-12 (Fig. 2) than the independent predictions of the multisurface model. It should be noted however that these partition relations were not tested on independent data. Furthermore, the solution data in data set "pH-stat" were obtained by adding acid and base to arrive at $\mathrm{pH}$-values which were far from the original $\mathrm{pH}$ of the soils. This $\mathrm{pH}$ change will also lead to changes in parameters influencing trace element solubility, not accounted for in the partition relations, such as the concentrations of $\mathrm{Al}$ and $\mathrm{P}$. At extreme $\mathrm{pH}$, these parameters might be far from steady state values in the field. We therefore recommend further testing of these (extended) relations before applying them for predictions of trace element solubility in field soils.

The multisurface model generally gives better predictions for the elements for which the model parameters are based on extended data sets: $\mathrm{Cd}, \mathrm{Cu}, \mathrm{Ni}$ and $\mathrm{Zn}$ (Fig. 2). However for the oxyanions and cations for which the parameterization is derived from relatively few data or LFER, the predictions by the multisurface model were less successful than those by the extended partition model. This finding further stresses the need to develop or improve (intrinsic) model parameters for these elements; suggestions are listed in (Dijkstra et al., 2009). Further improvements can be made by including the interaction of DOM with oxide surfaces and its effect on oxy-anion binding (Gustafsson, 2006; Weng et al., 2009). For the metal cations that are already predicted well, the extent of further improvements will be limited by intrinsic uncertainties related to the heterogeneous character of natural organic matter (Groenenberg et al., 2010a) and other reactive soil constituents.

A particular advantage of multisurface models, which widens their potential use, is their process based character, including their explicit account for interactions between elements, in combination with "generic" parameters that have been derived over a wide domain of conditions such as $\mathrm{pH}$ and ionic strength (Dzombak and Morel, 1990; Milne et al., 2003). These features make them suitable as research tools (i.e. to test hypotheses) and applicable beyond the domain of (presently available) partition-relations Examples are the use of multisurface models for very acid and alkaline systems, e.g. acid-mine-drainage (Butler et al., 2008) and waste materials such as MSWI-bottom ash (Dijkstra et al., 2008). Furthermore the explicit account of interactions between trace elements and major elements ( $\mathrm{Ca}, \mathrm{Al}, \mathrm{Fe}, \mathrm{P}, \mathrm{S}$ ) enables the use of multisurface models for a wider range of conditions as well as for changing conditions, e.g. to predict the effect of P-fertilization on trace element solubility.

However, various choices are to be made when applying multisurface models to natural systems, which lead to a certain conditionality. Examples are the different choices made to quantify: (1) reactive element contents using various acidic extracts 
(Schröder et al., 2005; Almas et al., 2007; Dijkstra et al., 2009) or EDTA (Bonten et al., 2008a); (2) Al/Fe/Mn-(hydr)oxide contents using various extracts, e.g. oxalate (Bonten et al., 2008a) or a combination of dithionite and ascorbate (Dijkstra et al., 2009) and (3) the concentrations of HS which are usually estimated to be a fraction of SOM and DOM between 50\% (Lofts and Tipping, 1998) and $100 \%$ (Almas et al., 2007). Bonten et al. (2008a) have shown that multisurface models may also obtain conditionality at high element concentrations when appropriate minerals are to be chosen in the absence of independent mineralogical analyses. Therefore, insight is needed in the model sensitivity to these different choices and quantification of the resulting model uncertainty, in particular when models are used for (generic) risk assessment purposes.

Apart from the aforementioned advantages and constraints, multisurface models provide predictions of the speciation of elements in the solid and the solution phase. Such information is required in (terrestrial) Biotic Ligand Models (Thakali et al., 2006) and in models which account for kinetic binding to a certain constituent, e.g. the slow kinetic binding of trace metals by hydrous oxides (Buekers et al., 2008). Another potential is the use of multisurface models in the dynamic forward prediction of the macro chemistry of natural systems and its subsequent effect on the solubility of trace elements, e.g. in case of acidification (Fest et al., 2005; Bonten et al., 2011). In this respect one of the greatest challenges is to adequately predict the concentration of DOM, especially of the most reactive components therein with respect to ionbinding, i.e. humic and fulvic acids, which are currently major influential model input parameters (Groenenberg et al., 2010a).

\section{Conclusions}

1. Partition relations and process based multisurface models showed similar performance in their prediction of trace element concentrations in soil solutions in the most relevant $\mathrm{pH}$ range for soils of $3-8$.

2. The coefficients of the derived partition relations for metal cations comply with the common mechanistic understanding of cation binding in soils.

3. The $\mathrm{pH}$ dependence of the partition relations for oxy-anions is largely accounted for by the DOC coefficient in these regression relations. This relationship stems from a very similar $\mathrm{pH}$ dependent solubility of oxy-anions and dissolved organic carbon.

4. Multisurface models in combination with generic parameters can be used to predict element solubility for a very wide range of $\mathrm{pH}(2-12)$ without any parameter fitting. In addition, multisurface models provide predictions of the speciation of elements in the solid and the solution phase.

5. Partition relations can be derived for a similar wide $\mathrm{pH}$ range, but the adjusted parameters in these relations then often become more difficult to interpret mechanistically.

6. Predictive calculations with both type of models would strongly benefit from developments which would allow prediction of DOC concentrations in soils rather than relying on measurements of this frequently unavailable parameter.

\section{Acknowledgements}

We thankfully acknowledge Sonia Rodrigues for providing the Portuguese data and samples. This work is the result of a collaborative project by a consortium of RIVM, ECN and Alterra and was funded by the Ministry of Infrastructure and the Environment, SKB, the municipality of Tilburg and the Ministry of Economic Affairs, Agriculture and Innovation research-program KB-01.

\section{Appendix. Supplementary information}

Supplementary information related to this article can be found online at doi:10.1016/j.envpol.2012.03.011.

\section{References}

Almas, A.R., Lofts, S., Mulder, J., Tipping, E., 2007. Solubility of major cations and $\mathrm{Cu}$ $\mathrm{Zn}$ and $\mathrm{Cd}$ in soil extracts of some contaminated agricultural soils near a zinc smelter in Norway: modelling with a multisurface extension of WHAM. European Journal of Soil Science 58, 1074-1086.

Anderson, P.R., Christensen, T.H., 1988. Distribution coefficients of Cd, Co, Ni and Zn in soils. Journal of Soil Science 39, 15-22.

Baas Becking, L.G.M., Kaplan, I.R., Moore, D., 1960. Limits of the natural environment in terms of $\mathrm{pH}$ and oxidation-reduction potentials. Journal of Geology 68 $243-284$

Benedetti, M.F., van Riemsdijk, W.H., Koopal, L.K., Kinniburgh, D.G., Gooddy, D.C., Milne, C.J., 1996. Metal ion binding by natural organic matter: from the model to the field. Geochimica et Cosmochimica Acta 60, 2503-2513.

Bonten, L.T.C., Groenenberg, J.E., Meesenburg, H., De Vries, W., 2011. Using advanced surface complexation models for modelling soil chemistry under forests. The Solling case. Environmental Pollution 159, 2831-2839.

Bonten, L.T.C., Groenenberg, J.E., Weng, L., van Riemsdijk, W.H., 2008a. Use of speciation and complexation models to estimate heavy metal sorption in soils. Geoderma 146, 303-310.

Bonten, L.T.C., Römkens, P.F.A.M., Brus, D.J., 2008b. Contribution of heavy meta leaching from agricultural soils to surface water loads. Environmental Forensics 9, 252-257.

Buekers, J., Degryse, F., Maes, A., Smolders, E., 2008. Modelling the effects of ageing on $\mathrm{Cd}, \mathrm{Zn}, \mathrm{Ni}$ and $\mathrm{Cu}$ solubility in soils using an assemblage model. European Journal of Soil Science 59, 1160-1170.

Butler, B.A., Ranville, J.F., Ross, P.E., 2008. Observed and modeled seasonal trends in dissolved and particulate $\mathrm{Cu}, \mathrm{Fe}, \mathrm{Mn}$, and $\mathrm{Zn}$ in a mining-impacted stream. Water Research 42, 3135-3145.

De Vries, W., Römkens, P.F.A.M., Bonten, L.T.C., 2008. Spatially explicit integrated risk assessment of present soil concentrations of cadmium, lead, copper and zinc in the Netherlands. Water, Air, and Soil Pollution 191, 199-215.

Degryse, F., Smolders, E., Parker, D.R., 2009. Partitioning of metals (Cd, Co, Cu, Ni, Pb, $\mathrm{Zn}$ ) in soils: concepts, methodologies, prediction and applications - a review. European Journal of Soil Science 60, 590-612.

Dijkstra, J.J., Meeussen, J.C.L., Comans, R.N.J., 2009. Evaluation of a generic multisurface sorption model for inorganic soil contaminants. Environmental Science and Technology 43, 6196-6201.

Dijkstra, J.J., Meeussen, J.C.L., Van der Sloot, H.A., Comans, R.N.J., 2008. A consisten geochemical modelling approach for the leaching and reactive transport of major and trace elements in MSWI bottom ash. Applied Geochemistry 23, 1544-1562.

Dzombak, D.A., Morel, F.M.M., 1990. Surface Complexation Modeling: Hydrous Ferric Oxide. Wiley, New York.

Elzinga, E.J., van Grinsven, J.J.M., Swartjes, F.A., 1999. General purpose Freundlich isotherms for cadmium, copper and zinc in soils. European Journal of Soil Science 50, 139-149.

Fest, E.P.M.J., Temminghoff, E.J.M., Griffioen, J., Van Riemsdijk, W.H., 2005. Proton buffering and metal leaching in sandy soils. Environmental Science and Technology 39, 7901-7908.

Gooddy, D.C., Shand, P., Kinniburgh, D.G., van Riemsdijk, W.H., 1995. Field-based partition coefficients for trace elements in soil solutions. European Journal of Soil Science 46, 265-285.

Groenenberg, J.E., Koopmans, G.F., Comans, R.N.J., 2010a. Uncertainty analyses of the nonideal competitive adsorption-Donnan model: effects of dissolved organic matter variability on predicted metal speciation in soil solution. Environmental Science and Technology 44, 1340-1346.

Groenenberg, J.E., Römkens, P.F.A.M., Comans, R.N.J., Luster, J., Pampura, T. Shotbolt, L., Tipping, E., De Vries, W., 2010b. Transfer functions for solid solution partitioning of cadmium, copper, nickel, lead and zinc in soils: derivation of relations for free metal ion activities and validation on independent data European Journal of Soil Science 61, 58-73.

Gustafsson, J.P., 2001. Modeling the acid-base properties and metal complexation of humic substances with the Stockholm Humic Model. Journal of Colloid and Interface Science 244, 102-112.

Gustafsson, J.P., 2006. Arsenate adsorption to soils: modelling the competition from humic substances. Geoderma 136, 320-330.

Gustafsson, J.P., Van Schaik, J.W.J., 2003. Cation binding in a mor layer: batch experiments and modelling. European Journal of Soil Science 54, 295-310.

Hiemstra, T., Van Riemsdijk, W.H., 1996. A surface structural approach to ion adsorption: the charge distribution (CD) model. Journal of Colloid and Interface Science 179 , 488-508.

Janssen, R.P.T., Peijnenburg, W.J.G.M., Posthuma, L., van den Hoop, M.A.G.T., 1997 Equilibrium partitioning of heavy metals in Dutch field soils. I. Relationship between metal partition coefficients and soil characteristics. Environmental Toxicology and Chemistry 16, 2470-2478.

Khai, N.M., Öborn, I., Hillier, S., Gustafsson, J.P., 2008. Modeling of metal binding in tropical Fluvisols and Acrisols treated with biosolids and wastewater. Chemosphere $70,1338-1346$. 
Kinniburgh, D.G., Van Riemsdijk, W.H., Koopal, L.K., Borkovec, M., Benedetti, M.F., Avena, M.J., 1999. Ion binding to natural organic matter: competition, heterogeneity, stoichiometry and thermodynamic consistency. Colloids and Surfaces A: Physicochemical and Engineering Aspects 151, 147-166.

Koopal, L.K., Van Riemsdijk, W.H., Kinniburgh, D.G., 2001. Humic matter and contaminants. General aspects and modeling metal ion binding. Pure and Applied Chemistry 73, 2005-2016.

Koopmans, G.F., Groenenberg, J.E., 2011. Effects of soil oven-drying on concentrations and speciation of trace metals and dissolved organic matter in soil solution extracts of sandy soils. Geoderma 161, 147-158.

Lofts, S., Tipping, E., 1998. An assemblage model for cation binding by natural particulate matter. Geochimica et Cosmochimica Acta 62, 2609-2625.

McBride, M.B., 1994. Environmental Chemistry of Soils. Oxford University Press, New York.

Milne, C.J., Kinniburgh, D.G., Van Riemsdijk, W.H., Tipping, E., 2003. Generic NICA Donnan model parameters for metal-ion binding by humic substances. Environmental Science and Technology 37, 958-971.

Rodrigues, S.M., Henriques, B., Ferreira da Silva, E., Pereira, M.E., Duarte, A.C., Groenenberg, J.E., Römkens, P.F.A.M., 2010. Characterization of total, reactive and available pools of twenty potentially toxic elements in Portuguese soils: Part II - Analysis of solid-solution partition relationships and ion activity in soil solutions. Chemosphere $81,1560-1570$.

Sauvé, S., Hendershot, W., Allen, H.E., 2000. Solid-solution partitioning of metals in contaminated soils: dependence on $\mathrm{pH}$, total metal burden and organic matter. Environmental Science and Technology 34, 1125-1131.

Sauvé, S., McBride, M.B., Hendershot, W.H., 1997a. Speciation of lead in contaminated soils. Environmental Pollution 98, 149-155.

Sauvé, S., McBride, M.B., Norvell, W.A., Hendershot, W.H., 1997b. Copper solubility and speciation of in situ contaminated soils: effects of copper level, pH and organic matter. Water, Air, and Soil Pollution 100, 133-149.

Schröder, T.J. Hiemstra, T., Vink, J.P.M., Van Der Zee, S.E.A.T.M., 2005. Modeling of the solid-solution partitioning of heavy metals and arsenic in embanked flood plain soils of the rivers rhine and meuse. Environmental Science and Technology 39, 7176-7184.

Thakali, S., Allen, H.E., Di Toro, D.M., Ponizovsky, A.A., Rodney, C.P., Zhao, F.J., McGrath, S.P., 2006. A Terrestrial Biotic Ligand Model. 1. Development and application to $\mathrm{Cu}$ and $\mathrm{Ni}$ toxicities to barley root elongation in soils. Environmental Science and Technology 40, 7085-7093.

Tipping, E., 1998. Humic ion-binding model VI: An improved description of the interactions of protons and metal ions with humic substances. Aquatic Geochemistry 4, 3-48.

Tipping, E., Lawlor, A.J., Lofts, S., Shotbolt, L., 2006. Simulating the long-term chemistry of an upland UK catchment: heavy metals. Environmental Pollution 141, 139-150.

Tipping, E., Rieuwerts, J., Pan, G., Ashmore, M.R., Lofts, S., Hill, M.T.R., Farago, M.E., Thornton, I., 2003. The solid-solution partitioning of heavy metals $(\mathrm{Cu}, \mathrm{Zn}, \mathrm{Cd}$, $\mathrm{Pb}$ ) in upland soils of England and Wales. Environmental Pollution 125, 213-225.

Van Riemsdijk, W.H., Koopal, L.K., Kinniburgh, D.G., Benedetti, M.F., Weng, L., 2006. Modeling the interactions between humics, ions, and mineral surfaces. Environmental Science and Technology 40, 7473-7480.

Verschoor, A.J., Lijzen, J.P.A., van den Broek, H.H., Cleven, R.F.M.J., Comans, R.N.J., Dijkstra, J.J., 2008. Revision of the Dutch building materials decree: alternative emission limit values for inorganic components in granular building materials In: 9th International Symposium on Environmental Geotechnology and Global Sustainable Development, Hong Kong.

Vijver, M.G., Spijker, J., Vink, J.P.M., Posthuma, L., 2008. Determining metal origins and availability in fluvial deposits by analysis of geochemical baselines and solid-solution partitioning measurements and modelling. Environmental Pollution 156, 832-839.

Weng, L., Temminghoff, E.J.M., Van Riemsdijk, W.H., 2001. Contribution of individual sorbents to the control of heavy metal activity in sandy soil. Environmental Science and Technology 35, 4436-4443.

Weng, L., Van Riemsdijk, W.H., Hiemstra, T., 2009. Effects of fulvic and humic acids on arsenate adsorption to goethite: experiments and modeling. Environmental Science and Technology 43, 7198-7204. 